Review

\title{
Ionic Liquids as Advanced Lubricant Fluids
}

\author{
María-Dolores Bermúdez *, Ana-Eva Jiménez, José Sanes and Francisco-José Carrión \\ Grupo de Ciencia de Materiales e Ingeniería Metalúrgica, Departamento de Ingeniería de Materiales y \\ Fabricación, Universidad Politécnica de Cartagena, Campus Muralla del Mar. 30202-Cartagena, Spain
}

* Author to whom correspondence should be addressed; E-mail: mdolores.bermudez@upct.es

Received: 17 July 2009; in revised form: 30 July 2009 / Accepted: 3 August 2009 /

Published: 4 August 2009

\begin{abstract}
Ionic liquids (ILs) are finding technological applications as chemical reaction media and engineering fluids. Some emerging fields are those of lubrication, surface engineering and nanotechnology. ILs are thermally stable, non-flammable highly polar fluids with negligible volatility, these characteristics make them ideal candidates for new lubricants under severe conditions, were conventional oils and greases or solid lubricants fail. Such conditions include ultra-high vacuum and extreme temperatures. Other very promising areas which depend on the interaction between IL molecules and material surfaces are the use of ILs in the lubrication of microelectromechanic and nanoelectromechanic systems (MEMS and NEMS), the friction and wear reduction of reactive light alloys and the modification of nanophases.
\end{abstract}

Keywords: ionic liquids; surface interactions; tribochemistry; additives; nanotechnology

\section{Introduction}

Salts with melting points lower than $100{ }^{\circ} \mathrm{C}$ are called ionic liquids. In this work, we will refer mainly to room-temperature ionic liquids, which present melting points lower than room temperature. In what follows we will use the general abbreviation IL to refer to ionic liquids and room-temperature ionic liquids. ILs are usually composed of an organic cation, typically containing nitrogen or phosphorus, and a weakly coordinating anion. Some of the most common cations (Figure 1) are imidazolium, phosphonium, pyridinium and ammonium, while some common anions are $\mathrm{BF}_{4} ; \mathrm{PF}_{6}$; $\mathrm{CF}_{3} \mathrm{SO}_{3}$ and $\mathrm{N}\left(\mathrm{CF}_{3} \mathrm{SO}_{2}\right)_{2}$. 
Figure 1. Some common IL cations used in lubrication and surface modification.

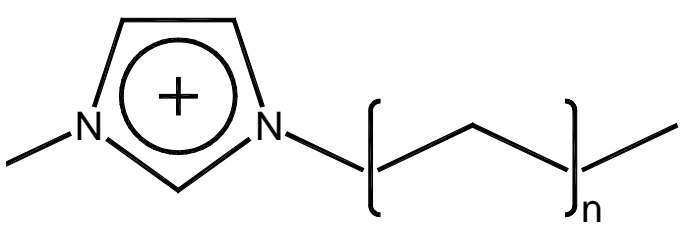

Imidazolium

$\left[\mathrm{R}_{4} \mathrm{~N}^{+}\right]$

Ammonium

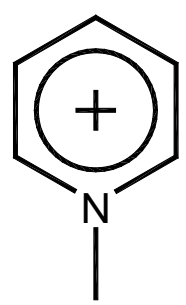

$\mathrm{R}$

Pyridinium

$\left[\mathrm{R}_{4} \mathrm{P}^{+}\right]$

Phosphonium

The possibility of tuning the chemical and physical properties by changing the anion-cation combination is a great opportunity to obtain task-specific ILs. Understanding their structural properties [1-3] is essential for a systematic design.

Although some ILs can be distilled under vacuum at $200-300{ }^{\circ} \mathrm{C}$ [4], they present a negligible vapour pressure. Other unique characteristics of ILs are their high polarity, high thermal stability, nonflammability, miscibility with water and with organic solvents and their electrochemical properties. This combination is responsible for their growing number of applications, mainly in chemical synthesis and extraction processes, but also as engineering fluids [5-11], in nanotechnology or even pharmaceutical processes [12]. The intense interest in the ILs field raised in the last decade has been universal and interdisciplinary, and it has lead to advances both in fundamental knowledge and in technological applications [13].

Most literature references deal with the synthesis, physicochemical properties and characterization of ILs. Some recent reviews [5-13] have also focused on applications as solvent replacement, purification of gases, homogenous and heterogeneous catalysts, biological reactions media and removal of metal ions, electrolytes in batteries, lubricants, plasticizers, solvents and catalysts in synthesis, matrices for mass spectroscopy, solvents in the controlled synthesis of nanomaterials, extraction, gas absorption agents, etc.

Applications in which ILs are used as novel engineering fluids are based on their solubility, their thermal and mechanical properties or some combination of these. These include their use as thermometric fluids in liquid-in-glass thermometers [7] or their use in a lunar telescope [14]. The negligible vapour pressure, substantial conductivities and thermal stability of ionic liquids make them ideal candidates for space applications, such as the compression of oxygen using an IL as operating fluid. For use in high pressure applications they should have low compressibility, adjustable gas solubility and good lubricating ability.

A recent review [11], highlights advances of ILs as versatile green engineering liquids in a variety of industrial applications including heat transfer fluids, azeotrope-breaking liquids, lubricants, electrolytes, liquid crystals, supported IL membranes, etc. Interactions between two solvents such as ILs and supercritical $\mathrm{CO}_{2}$ are also being studied [10]. 
During the last decade, ILs have established themselves as promising advanced lubricants due to many of the same properties that make them useful as solvents and engineering fluids. The study of friction, wear and lubrication is the subject of study of the interdisciplinary field of tribology. A review by I. Minami in this same issue is dedicated to ionic liquids in tribology [13]. Closely related to the efficiency of ionic liquid as lubricants, are the surface interactions which take place at the material-IL interface.

The present review will focus on the possibility of using ILs as lubricants in aqueous environments (water is a truly green lubricant in the room temperature range) or under severe conditions for which conventional lubricants fail, such as those found in spacecraft applications: ultra-high vacuum and extreme temperatures (from cryogenic conditions up to $500{ }^{\circ} \mathrm{C}$ ). We will also highlight the use of ILs in contact with difficult to lubricate materials such as the light alloys, due to their reactivity towards conventional lubricants, and in nanotechnology, where IL molecules act as surface modifiers of nanoparticles and nanotubes, or in lubrication of MEMS or NEMS systems, and nanocomposites.

Tribosystems are present in all mobile mechanisms, from automotive, industrial, domestic, to aerospace applications. In tribosystems, one material slides against another or against itself. Even in this latter case, the geometry of the counterparts can be different and the contact is then asymmetric. For each combination of materials and contact configurations, the tribological variables include normal applied load, sliding distance, speed and frequency, temperature (ambient and contact temperature), atmosphere, moisture, etc. The geometry of the contact and the contact pressure change when one or both materials are worn during the sliding process. When wear debris are trapped at the contact zone, a third body is formed which can protect against further material removal or increase the surface damage by abrasion due to ploughing.

Lubricants are used to control friction and wear preventing direct contact between the surface asperities of the materials and lowering the contact temperature. Lubricant formulation is based on a mineral or synthetic base oil or grease with a mixture of different additives to control viscosity, surface interactions, corrosion and increase load carrying capacity, thermal diffusivity and service life. However, commercial lubricants are derived form petroleum, present environmental problems and are not suitable for many materials and conditions. The need for new effective, environmentally friendly lubricants is clear, as the losses due to friction and wear of materials can be estimated around a $1.5 \%$ of the gross domestic product (GDP) of industrialized countries [15].

\section{IL as Neat Lubricants}

ILs based upon the 1-n-alkyl-3-methylimidazolium cation were first reported in 1982 by Wilkes et al. [16]. In 1992, Wilkes and Zaworotko [17] developed an air and water stable ionic liquid based upon the tetrafluoroborate anion. These water stable ILs were the first ones selected as lubricants.

The field of IL lubrication was effectively started in 2001 by Liu et al. [18]. They studied alkylimidazolium tetrafluoroborates in steel/steel, steel/aluminium, steel/copper, steel/ $\mathrm{SiO}_{2}$, steel/ $\mathrm{Si}(100)$, steel/sialon and $\mathrm{Si}_{3} \mathrm{~N}_{4} /$ sialon ceramic contacts, showing excellent friction reduction.

The interest of these results has steadily increased the number of scientific papers published each year (Figure 2) only on IL lubrication until June 2009, according to the Thomson ISI Web of Knowledge database. 
Figure 2. Evolution of the number of scientific papers published on the use of ILs in lubrication.

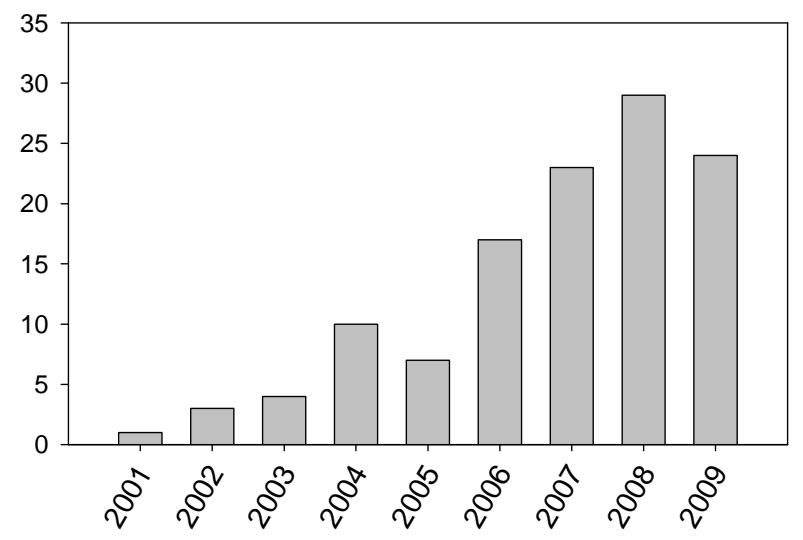

From the first works [18-21], the good lubricating performance of ILs was attributed to the surface interactions and tribochemical processes, which take place at the interface. Adsorption of IL molecules and formation of surface layers containing $\mathrm{B}_{2} \mathrm{O}_{3}$ and $\mathrm{BN}$ was proposed on the basis of X-ray photoelectron spectroscopy (XPS) analysis.

The real time in-situ formation of $\mathrm{FeF}_{2}$ by tribochemical reaction between 1-ethyl-3-methylimidazolium tetrafluoroborate $\left([\mathrm{EMIM}] \mathrm{BF}_{4}\right)$ and steel at room temperature has been demonstrated [22].

Most works on IL lubrication refer to steel-steel contacts, which are the most common. The main results obtained are reviewed by Minami [13]. Industries where the tribological considerations are critical are those of transport, where conventional alloys are being substituted by light alloys, and aerospace applications where severe conditions such as extreme temperatures, corrosive environments or high vacuum predominate. These are the areas where ILs can fill a gap. In what follows, we will review some of the main results obtained in these fields.

\section{ILs as Lubricants of Light Alloys}

A major goal of the present research in tribology is to find effective lubricants for reactive light alloys such as magnesium [23-29], aluminium [30-40] and titanium [41]. These alloys are substituting conventional iron-based materials due to their lower densities, higher specific resistance and the ability to form corrosion-protective surface layers. However, surface interactions with IL molecules could also promote corrosive attack.

Although several works have been dedicated to study the interactions between imidazolium based ionic liquid and reactive magnesium alloys [23-29], to our knowledge, the use of ILs as lubricants of magnesium alloys has not been reported.

The development of protective surface films on a magnesium alloy has been described [27]. The film results from the reactivity between magnesium and the IL and improves the corrosion resistance of the alloy. It remains to be studied if it could also provide higher wear resistance.

Titanium exhibits outstanding corrosion resistance in a wide variety of environments, specially oxidizing, neutral and inhibiting reducing media. The corrosion resistance of titanium is due to the 
formation of a protective and self-adherent oxide film. Nevertheless, this film is not stable in reducing acids and titanium is severely attacked.

Recently [38], ammonium and imidazolium ILs were studied as lubricants of titanium, finding that for both types of cations, a longer side chain gave better antiwear protection for titanium. At room temperature, the best performance was obtained for 1-methyl-3-benzylimidazolium chloride $([\mathrm{BzMIM}] \mathrm{Cl})$, while at $100{ }^{\circ} \mathrm{C}$, the lowest friction and wear values were obtained for 1-hexyl-3methyl-imidazolium hexafluorophosphate $\left(\left[\mathrm{HMIM} \mathrm{PF}_{6}\right)\right.$. Again, the lubrication results are related to tribochemical processes. Tetrafluoroborate imidazolium ILs decompose at the metal-metal contact producing severe tribocorrosion, with formation of metallic fluorides, boron carbide and boron oxide. In contrast, under the conditions studied, the hexafluorophosphate lubricant forms adsorbed layers on the titanium surface and a phosphate-containing protective layer on the steel counterface.

Among the light alloys, the most studied are aluminium alloys due to their wide range of application in sliding components, particularly in the automotive industry.

A series of room temperature ionic liquids with phosphonyl groups on the imidazolium cation, 1(3'-O,O-diethylphosphonyl-n-propyl)-3-alkylimidazolium tetrafluoroborate, were prepared [31] and evaluated as promising lubricants for the contact of aluminum on steel. The new functionalized imidazolium ILs with lateral phosphonyl groups showed superior tribological performance as neat lubricants of steel/aluminium contacts than nonfunctionalized alkylimidazolium derivatives, due to surface interactions through the phosphorus atoms. The formation of films composed of bridged complex compounds, metal fluorides, nitrogen oxide, $\mathrm{B}_{2} \mathrm{O}_{3}, \mathrm{BN}$, and $\mathrm{FePO}_{4}$ on the rubbed surfaces was proposed.

The influence of the alkyl chain length on the cation and that of the anion on the lubricating ability has been studied for 1-n-alkyl-3-methylimidazolium ILs in steel/aluminium contacts [32]. Real-time sharp friction increments (Figure 3) related to tribochemical processes have been observed for tetrafluoroborate and hexafluorophosphate ILs, at room-temperature and at $100{ }^{\circ} \mathrm{C}$.

Figure 3. Friction records and appearance of the aluminium surface covered by IL after the test: a) Low constant friction in the absence of tribocorrosion; b) Friction increase due to tribocorrosion.

a)

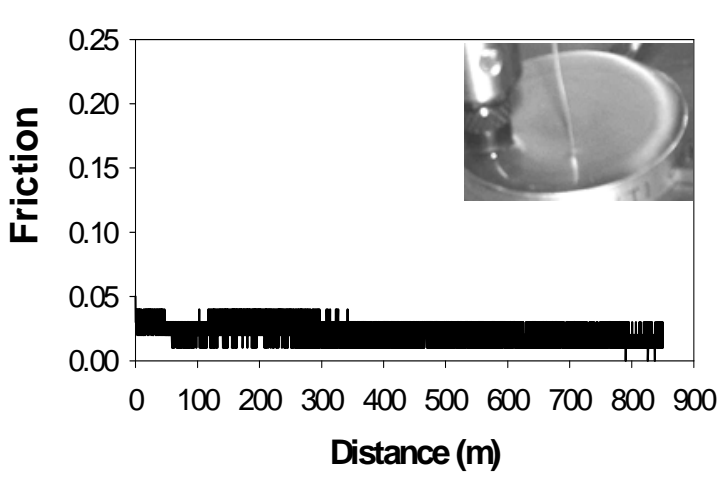

b)

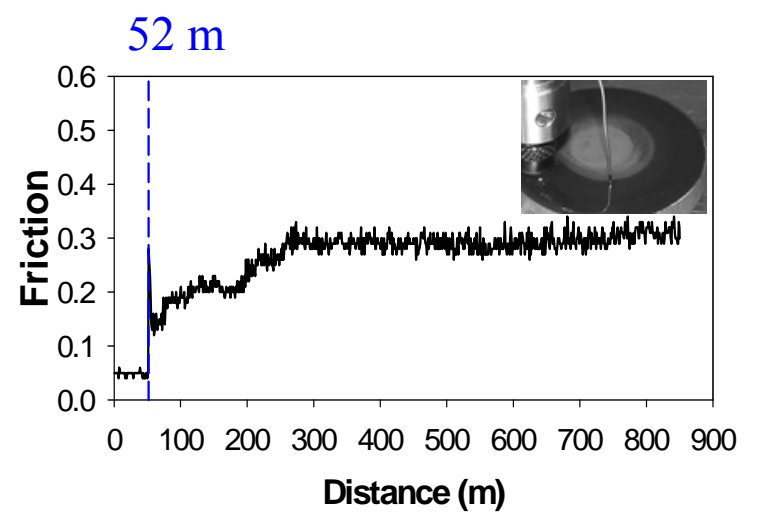

Wear scar surfaces are oxidized to $\mathrm{Al}_{2} \mathrm{O}_{3}$ and wear debris contain aluminium and iron fluorides, in the case of tetrafluoroborate ILs. For hexafluorophosphate ILs, the steel surface is covered with a 
phosphorus-containing tribolayer. A change of anion reduces friction and wear, but the lowest values are obtained by increasing the alkyl chain length on the imidazolium cation.

Although imidazolium ILs constitute the more extensively studied family of IL lubricants, other cations have been also used in a more limited number of studies, with promising results in the case of ammonium derivatives [37,38]. A quaternary ammonium ionic liquid crystal was shown to have superior performance under severe contact conditions in steel/aluminium lubrication than neutral liquid crystals [39]. A series of trialkylammonium ionic liquids were synthesized by neutralization and metathesis reactions, and have demonstrated promising lubricating properties as neat lubricants or lubricant additives, particularly for use with difficult to lubricate metals like aluminium.

Different aluminium alloys have been studied in the presence of trialkylammonium and imidazolium ILs at room temperature and at $100{ }^{\circ} \mathrm{C}[37,38]$. Results depend on the aluminium alloyIL surface interactions, thus showing that each material-IL pair needs to be evaluated independently before general conclusions can be reached. Surface interactions of alkylimidazolium ionic liquids (ILs) with aluminium alloys have been studied [40] by immersion tests in seven neat ILs, six imidazolium ILs and one pyridinium derivative. Immersion tests have also been carried out in 1 wt.\% and 5 wt.\% solutions of 1-ethyl-3-methyl-imidazolium tetrafluoroborate $\left([\mathrm{EMIM}] \mathrm{BF}_{4}\right)$ in water. No corrosion of $\mathrm{Al}$ by the neat ILs is observed. The highest corrosion rate for $\mathrm{Al}$ in water is observed in the presence of a $5 \mathrm{wt} . \%$ [EMIM]BF 4 , probably due to hydrolysis of the anion and formation of aluminium fluoride.

Erosion-corrosion processes have been studied for three aluminium alloys in a $90 \mathrm{wt} \%$ [EMIM] $\mathrm{BF}_{4}$ solution in water in the presence of $\alpha$-alumina particles [40]. The erosion-corrosion rates are around $0.2 \mathrm{~mm} /$ year or lower, and increase with increasing copper content, thus showing that the interactions with ILs need to be determined for each set of conditions, considering the material and IL composition.

\section{ILs as Lubricants under High Vacuum}

Liu et al.'s [19] preliminary studies included ionic liquid lubrication at $100{ }^{\circ} \mathrm{C}$ and in vacuo, finding that the wear rate of steel was lower in vacuo in the presence of an alkylimidazolium tetrafluoroborate, thus anticipating that ILs could provide effective lubrication in space applications.

Alkylimidazolium hexafluorophosphate ILs were studied as lubricants of steel/steel contacts under vacuum $[42,43]$, showing superior performance than conventional oils, even modified by antiwear additives. The formation of $\mathrm{FePO}_{4}$ and $\mathrm{FeF}_{2}$ as a result of the tribochemical reaction of the IL and the steel surface was determined by XPS.

Tribological characteristics of two imidazolium-based ILs, 1-hexyl-3methylimidazolium tetrafluoroborate ([HMIM]BF 4 ), and 1-hexyl-3-methylimidazolium hexafluorophosphate ([HMIM] $\mathrm{PF}_{6}$ ) were investigated under high vacuum conditions [42]. Viscosity-temperature characteristics and thermogravimetric characteristics of these compounds were also investigated. Imidazolium-based ILs have relatively good viscosity-temperature characteristics that are comparable to those of multiplyalkylated cyclopentane. Thermogravimetric results showed that ILs have high thermal stability and low vapour pressure. ILs showed low friction and low wear rate under high vacuum conditions, and high load-carrying capacity was observed. 


\section{ILs as Extreme Temperature Lubricants}

The surface chemistry of IL-lubricated steel in sliding contact at temperatures from room to $300{ }^{\circ} \mathrm{C}$ has been studied [44]. Some iron samples were oxidized to $\mathrm{Fe}_{2} \mathrm{O}_{3}$ and $\mathrm{Fe}_{3} \mathrm{O}_{4}$ prior to treatment with ionic liquids. The metallic and oxidized samples were then reacted with ionic liquids at elevated temperatures. Chemical analysis revealed corrosion of the surface due to reaction between the ILs and the steel/iron substrates.

A series of new polyethylene glycol functionalized dicationic ILs with alkyl or polyfluoroalkyl substitutents has been prepared [45]. These ILs show high thermal stability and good lubricity. In general, imidazolium based dicationic liquids have higher degradation temperature $\left(\mathrm{T}_{\mathrm{d}}>400{ }^{\circ} \mathrm{C}\right)$ than their triazolium analogues. The introduction of polyfluoroalkyl groups boosts antiwear properties but also leads to a decrease in $T_{d}$. The dicationic ILs also exhibit excellent tribological characteristics even at $300{ }^{\circ} \mathrm{C}$, which suggests their potential as high temperature lubricants.

A new class of dicationic ionic liquids with a bridging moiety, such as a polyalkylether, polyfluoroalkyl, 1,4-bismethylenebenzene, or 1,4-bismethylene-2,3,5,6-tetrafluorobenzene, between the alkyl-substituted imidazolium rings has been described [46]. Their properties were modified by varying the linker chains and/or alkyl substituents on the imidazolium ring. These new ionic liquids (except with $\mathrm{PF}_{6}$ as anion) displayed outstanding tribological properties in temperature ramp tests by performing very well at $300{ }^{\circ} \mathrm{C}$, thus meeting one criterion for high-temperature lubricants.

The first study of ILs as steel-aluminium lubricants under a wide range of temperature conditions $\left(-30,100\right.$, and $\left.200{ }^{\circ} \mathrm{C}\right)$ [33] compares the tribological performance of the imidazolium ionic liquids 1-hexyl- and 1-octyl-3-methylimidazolium tetrafluoroborates ([HMIM]BF $\mathrm{B}_{4}$ and [OMIM]BF 4 , respectively) with that of a mineral oil and the synthetic ester propylene glycol dioleate in aluminiumsteel contacts. ILs show lower friction and wear values than conventional oils at all temperatures.

The lubricating performance depends on thermal stability, polarity of the molecules, their ability to form ordered adsorbed layers and the tribocorrosion processes which take place at the interface. While the conventional oils fail above $150{ }^{\circ} \mathrm{C}$ due to thermal decomposition, the longer alkyl chain $[\mathrm{OMIM}] \mathrm{BF}_{4}$ presents higher viscosity values than $[\mathrm{HMIM}] \mathrm{BF}_{4}$, and provides an effective surface separation at all temperatures, and only shows friction and wear increments at $-30{ }^{\circ} \mathrm{C}$ in the presence of water, due to severe abrasion by ice crystals.

Figure 4. Friction $(\mu)$ vs. sliding distance $(\mathrm{m})$ for steel-aluminium contact lubricated with [HMIM]PF 6 at $200{ }^{\circ} \mathrm{C}[33]$.

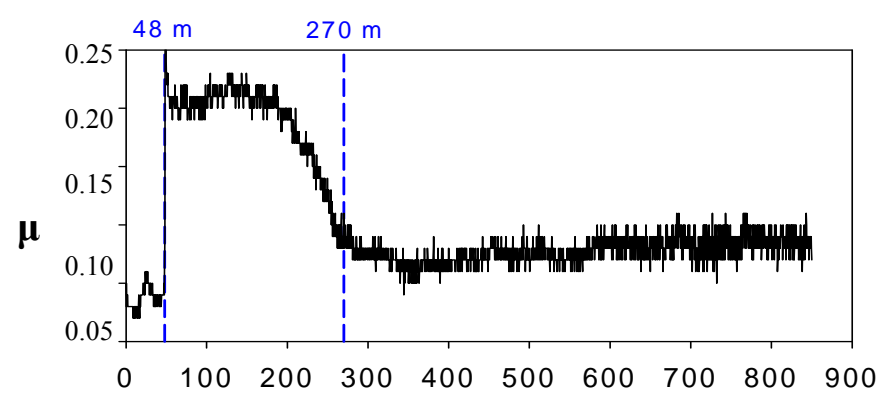


The more polar molecules of the shorter alkyl chain $[\mathrm{HMIM}] \mathrm{BF}_{4}$ produce severe wear at $200{ }^{\circ} \mathrm{C}$ due to the formation of aluminium fluoride wear debris by tribocorrosion reactions. The time for tribocorrosion to take place, has been determined from friction increments (see Figure 4) and wear debris generation.

\section{Surface Interactions}

In order to understand the complex surface chemistry which takes place at the materials-IL interfaces, most of the reported tribological works contain detailed surface interactions studies by XPS, particularly in the case of ceramic and metal lubrication with imidazolium hexafluorophosphates and tetrafluoroborates.

The general process which takes place includes oxidation, dissociation of the anions, formation of metallic phosphates, oxides and fluorides, and precipitation of ceramic phases such as boron and phosphorus fluorides, boron oxide, boron carbide, and boron nitride. Decomposition of the imidazolium cation with formation of nitrogen oxides has also been proposed. During the wear process, nascent metallic surfaces are produced which could enhance the metal-IL reactivity and favour the process of IL decomposition.

When the formation of bridge complexes between the surfaces and the IL molecules is favoured due to the presence of substituents with electron-donor atoms, the adsorbed IL layers are more stable and protect the surface.

For effective lubrication, these stable adsorbed tribolayers must combine with the presence of flexible units. The length of these units is a critical parameter in the antiwear properties as it determines the polarity of the IL.

Interestingly, IL additives can be as effective, or even more effective than neat ILs in reducing friction and wear. This can be explained by the fact that a low proportion of IL (around 1wt.\%) contains a number of IL molecules which is enough to form stable adsorbed layers on the surface, but not to produce the severe tribocorrosive attack found for fluorine-containing short alkyl chain ILs.

Metallic alloys which form protective oxide layers such as aluminium, titanium, nickel, etc. are resistant to corrosion by immersion in neat $\mathrm{IL}$, but when they are sliding against a more reactive counterface such as the bearing steel found in many moving parts, the decomposition of the IL is promoted due to the reaction with iron. The decomposition products can then react with the more corrosion resistant materials, giving rise to sharp friction and wear increases, as we have seen in Figures 3(b) and 4.

\section{Theoretical Studies and Models for IL Lubrication}

A scaling concept based on relaxation theories of the liquid state has been proposed [47] to provide a general framework describing the dependency of viscosity with pressure and temperature. The viscosity-pressure coefficient was expressed in terms of a state-independent scaling exponent. This scaling factor was determined empirically. New equations for the pressure- and temperature-viscosity coefficients were derived for elastohydrodynamic lubrication. These relations can be applied over a broad range of thermodynamic conditions. The fluids considered include several ionic liquid 
compounds selected to represent molecules of different sizes and with diverse intermolecular interactions.

The interactions between selected ionic liquids and either an aluminium oxide or a silicon nitride surface have been modelled using semi-empirical methods [48]. The ionic liquids include a series of cationic imidazolium derivatives with hexafluorophosphate anion. The tribological properties of these ionic liquids are modelled using a smooth alumina surface (Figure 5).

Figure 5. $\mathrm{IL}_{-}-\mathrm{Al}_{2} \mathrm{O}_{3}$ surface interactions.

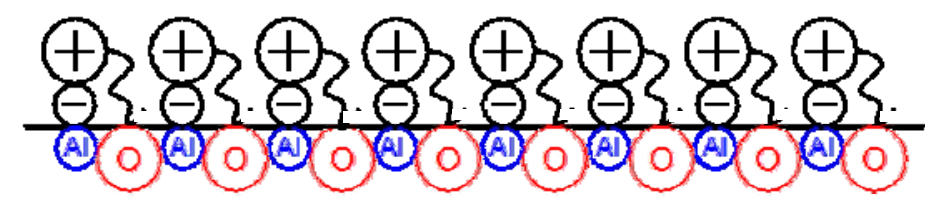

The ILs are allowed to form a complex with this surface and the enthalpies of complex formation are seen to correlate with the tribological properties of the seven ionic liquids. The ILs are also complexed with a hexagonal silicon nitride surface and their tribological properties are predicted on the basis of complex formation enthalpies.

Nanometer-scale structuring in ILs has been observed from theoretical simulations [2]. Segregation is observed for ILs of the 1-alkyl-3-methylimidazolium family with alkyl side chains in the cation longer than or equal to butyl. The alkyl chains aggregate in non-polar domains that permeate a threedimensional network of ionic channels formed by the charged parts of the ions, giving rise to mediumrange ordering.

In a very recent study on the frictional dynamics of alkylsilane monolayers on $\mathrm{SiO}_{2}$ [49] the simulations indicate that the molecules of the IL 1-butyl-3-methylimidazolium nitrate ([BMIM]NO$\left.)_{3}\right)$ could incorporate into a damaged area of the self-assembled monolayer (SAM) coating and restore the tribological properties of the film.

\section{Ionic Liquids as Lubricant Additives}

\section{ILs in water}

One remarkable characteristic of ILs is their organization in solution, with polar and non-polar domains [1-3] and their miscibility with polar and non-polar solvents. ILs have been used as lubricating additives both in water and in lubricating oils.

In the first work on the use of ionic liquids as lubricants, Liu et al. [18] already included a reference to the interactions of the IL lubricants studied with water, stating that the addition of a small amount of water $(\leq 5 \mathrm{wt} \%)$ to the ILs could help to improve the antiwear behavior for some metal-metal contacts.

When used as additives in water [50,51], ILs reduced the running-in period (the initial period of high friction) of ceramic-ceramic sliding contacts. The proposed mechanism was the initial smoothening of the surface by mechanical wear, the formation of $\mathrm{BF}_{\mathrm{x}}$ and $\mathrm{PF}_{\mathrm{x}}$ films on the surface and the creation of an electric double layer of IL molecules, which increases the local viscosity near the surface and the load carrying ability and lowers friction and wear. 
The lamellar microstructure composed by the non-ionic surfactant polyoxyethylene laurylether, the room temperature ionic liquid 1-butyl-3-methylimidazolium hexafluorophosphate ([BMIM] $\left.\mathrm{PF}_{6}\right)$ and water has been investigated [52]. The lubrication properties of the lamellar mesophase were determined to illustrate their relationship with the microstructure. The results showed that the structural strength of the lamellar phase is enhanced with increasing amount of the non-ionic surfactant, so the anti-wear capacity of the lamellar phase is improved.

\section{ILs as mineral oil additives}

1-n-Alkyl-3-methylimidazolium ILs, with different side chain lengths on the cations, and different fluorine-containing anions have been studied as mineral oil additives [36]. Figure 6 shows the effect of the addition of a $1 \mathrm{wt} . \%$ proportion of imidazolium ILs to a lubricant oil on the wear rate of aluminium at room temperature.

For the same anion $\left[\mathrm{BF}_{4}^{-}\right]$, the more effective neat ILs lubricants were those containing cations with longer alkyl chains: octyl- $\left(\left[\mathrm{OMIM}^{+}\right]\right)$better than hexyl- $\left(\left[\mathrm{HMIM}^{+}\right]\right)$and better than ethyl- ([EMIM $\left.\left.{ }^{+}\right]\right)$.

In contrast, when used as additives, the more effective wear reducing ILs are those with shorter alkyl chains: $\left[\mathrm{EMIM}^{+}\right]$better than $\left[\mathrm{HMIM}^{+}\right]$, better than $\left[\mathrm{OMIM}^{+}\right]$, as can be observed in Figure 6 . For the same cation $\left(\left[\mathrm{EMIM}^{+}\right]\right)$and different anions, the wear rate of aluminium decreases in the order: $\mathrm{MeC}_{6} \mathrm{H}_{4} \mathrm{SO}_{3}^{-}>\mathrm{CF}_{3} \mathrm{SO}_{3}^{-}>\mathrm{BF}_{4}^{-} .1$ wt.\% IL additives also show good lubricating performance at $100{ }^{\circ} \mathrm{C}$.

Figure 6. ILs as additives in steel-aluminium lubrication.

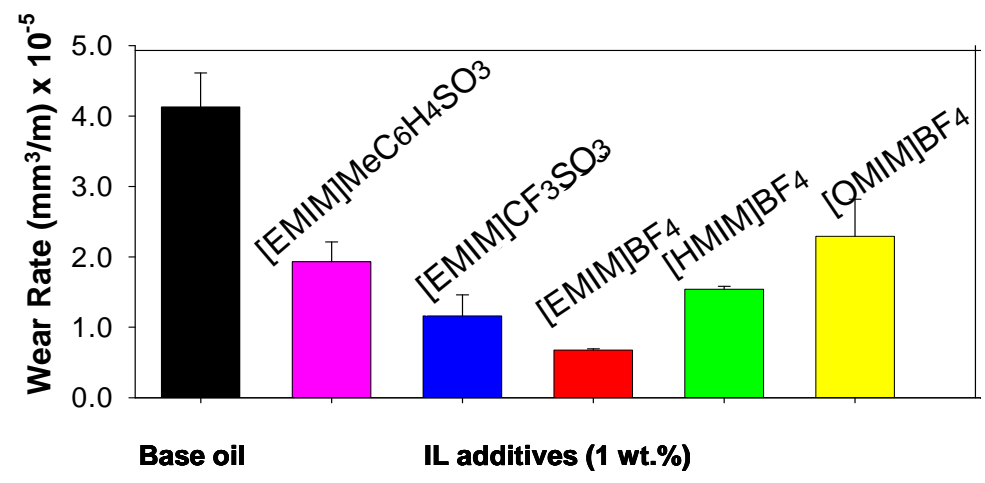

Wear rate is the material volume loss, in this case aluminium alloy, by unit of sliding distance.

\section{ILs as synthetic oil additives}

1-n-Alkyl-3-methylimidazolium ILs, with different side chain lengths and the fluorine-containing anions hexafluorophosphate $\left[\mathrm{PF}_{6}^{-}\right]$, tetrafluoroborate $\left[\mathrm{BF}_{4}^{-}\right]$and triflate $\left[\mathrm{CF}_{3} \mathrm{SO}_{3}^{-}\right]$have also been studied as $1 \mathrm{wt} . \%$ additives of the synthetic ester propylene glycol dioleate in steel-aluminium contacts at 25 and $100{ }^{\circ} \mathrm{C}$ [35]. At $100{ }^{\circ} \mathrm{C}$, all additives reduce both friction and wear with respect to the base oil. Friction coefficients for IL additives are similar or lower than for neat ILs, while wear rates for $1 \mathrm{wt} . \%$ ILs can be several orders of magnitude lower than those for neat ILs. In this case the contact conditions for optimum lubrication were the same for all additives independently of composition. 
Very recently [53], dicationic bis(imidazolium) ILs with the same long side-chain substituted cation and different anions were evaluated as additives in polyethylene glycol at room temperature. Results showed that they could effectively reduce the friction and wear of steel-steel sliding pairs compared with the base oil without additives. The dicationic IL with $\left[\left(\mathrm{CF}_{3} \mathrm{SO}_{2}\right)_{2} \mathrm{~N}^{-}\right]$anion showed better antiwear properties for an optimum concentration of $3 \mathrm{wt} . \%$.

IL additives not only reduce the friction and wear with respect to base oils, but they show better performance than neat ILs, as shown in Figure 7 [36] for steel-aluminium at room temperature, particularly for a determined sliding velocity which improves IL miscibility with the base oil.

The excellent tribological properties of IL additives are attributed to the formation of physically adsorbed films, formation of tribochemical products during friction without tribocorrosion, and good miscibility with the base oil.

Figure 7. Comparative antiwear performance of $\left[\mathrm{EMIM}^{+}\right]$ILs as neat lubricants and $1 \mathrm{wt} . \%$ additives [36].

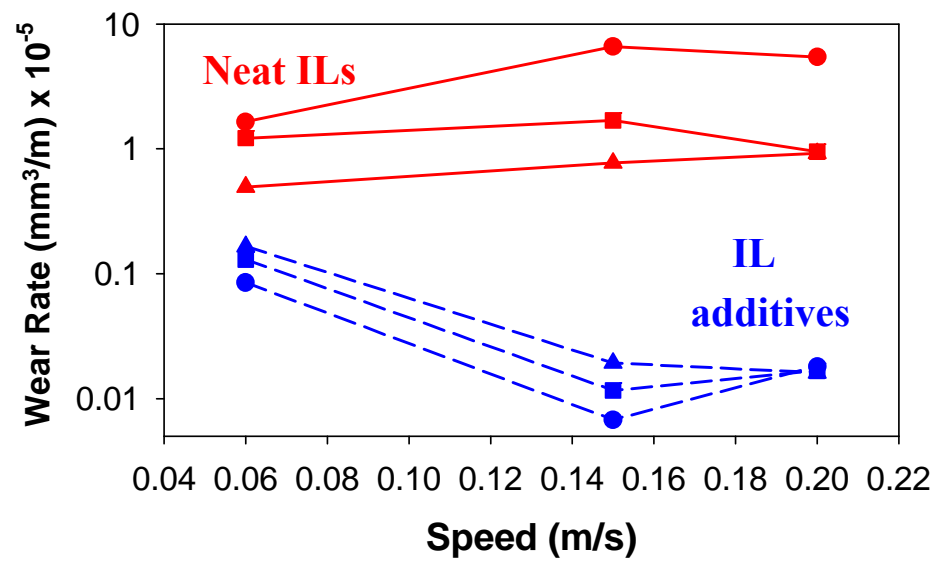

\section{Additives of IL lubricants}

In order to reduce the corrosive attack of the more reactive ILs, particularly those containing fluorine anions, several studies have attempted their modification by wear-reducing and corrosion inhibitor additives [54-58].

Benzotriazole (BTA) was studied as lubricant additive of ILs because of its similar molecular structure [54-56]. BTA can greatly improve the tribological behaviour of ILs with the hexafluorophosphate anion for the steel/Cu-Sn alloy sliding pair due to corrosion inhibition. Strong interaction between BTA and the surface of $\mathrm{Cu}$ alloy was proposed to account for the excellent antiwear and anti-corrosion improvement capability. In particular, a protective film containing $\left[\mathrm{Cu}\left(\mathrm{C}_{6} \mathrm{H}_{5} \mathrm{~N}_{3}\right)\right]$ and $\mathrm{Cu}_{2} \mathrm{O}$ has been proposed upon the basis of XPS analysis.

Diimidazoliumalkylene hexafluorophosphate ILs were synthesized and doped with BTA showing excellent anti-wear ability. The worn surfaces and chemical nature of the boundary films generated on the metal surfaces were analyzed. Results showed slight abrasion on the worn surfaces and XPS results indicated the formation of $\mathrm{FeF}_{2}, \mathrm{FeF}_{3}, \mathrm{Fe}_{3} \mathrm{O}_{4}$, and $\mathrm{FePO}_{4}$ by the tribochemical reactions of ionic liquid with iron during the sliding process. Tricresylphosphate (TCP) and dibenzyldisulfide additives have 
been found to improve antiwear properties of ILs to some extent. Minami et al. [57] have described the first additives that improve the tribological properties of ionic liquids. Tetraalkylammonium and tetraalkylphosphonium salts of $N$-protected aspartic acid was dissolved in 1-alkyl-3-methylimidzolium bis(trifluoromethylsulfonyl)imide. They prevented wear remarkably and reduced friction considerably. A model of boundary film composed of liquid clathrate structure was proposed.

Addition of 1\% TCP to ionic liquids [58] rapidly establishes a tribofilm and reduces the wear volume by $64 \%$ compared to the same test for the neat ionic liquid or neat TCP. Addition of $1 \%$ TCP and $1 \%$ IL to a base oil also establishes a substantial tribofilm and reduces wear volumes compared to the base oil with $1 \%$ TCP alone or the base oil with $1 \%$ ionic liquid alone.

ILs show promise as neat liquid lubricants by establishing a tribolayer chemically adsorbed to the steel surfaces, but they are not as effective as a reference hydrocarbon lubricant in reducing wear due to tribocorrosion. The fluorine-free ILs investigated were not as effective as those containing fluorine. The addition of ILs to grease, gave a substantial improvement in performance, which indicates a synergistic interaction with the additives present in the formulated grease. There is also clear evidence of a strong synergistic effect between ILs and TCP, but the nature of the synergy between ILs and TCP requires further investigation.

In the preceding sections we have reviewed the results obtained in conventional materials lubrication and conditions. In the following sections, some special applications and systems will be addressed.

\section{MEMS lubrication}

Palacio and Bushan [59] have studied the formation of ultra-thin wear resistant IL films for

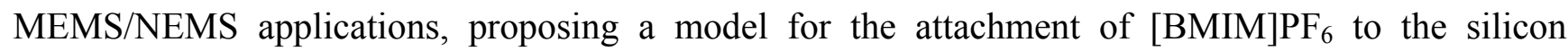
substrate (Figure 8).

Figure 8. Proposed model for the attachment of [BMIM]PF 6 to silicon [59].

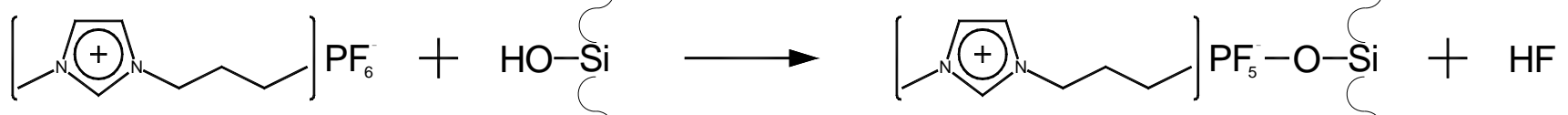

Contact failures in microelectromechanical system (MEMS) switches, particularly during hot switching, prevent their widespread use. A nanoparticle-liquid (NPL) lubricant is synthesized and deposited on MEMS switch contacts as a nanotechnology based lubricant [60]. NPLs are monolithic hybrid materials comprised of an inorganic nanosized metallic core and an organic low viscosity corona. The NPLs used contain Au or Pt nanoparticles as the core and a mercaptoethanesulfonate IL as the corona. NPLs exhibited improved electrical performance and durability as compared to uncoated and self-assembled monolayer-coated switch contacts. These results show that NPLs could have an excellent potential as surface modifiers/lubricants for MEMS switch contacts.

When MWCNTs are dispersed within a hexagonal lyotropic liquid crystals (LLCs) formed in the IL, ethylammonium nitrate [61], polarized optical microscopy images combined with small-angle X- 
ray scattering (SAXS) results indicate that the MWCNTs are well-dispersed and that the introduction of MWCNTs does not destroy the structure of hexagonal LLCs. The increase of $\mathrm{d}$ spacing demonstrates the integration of MWCNTs within the cylinders of the hexagonal LLCs.

The tribological properties were explored in order to extend the applications of MWCNTs-LLC composites in ILs as lubricating materials, although only macroscale friction and wear tests have been conducted on these materials. The rheological measurements indicated that MWCNTs-LLC composites are highly viscoelastic and that the apparent viscosity is enhanced by the presence of the MWCNTs.

ILs are considered as lubricants for micro/nanoelectromechanical systems (MEMS/NEMS) $[59,62,63]$ due to their excellent thermal and electrical conductivity. Evaluating the nanoscale tribological performance of ILs when applied as thin film on a substrate is a crucial step to understand how they can efficiently lubricate MEMS/NEMS devices.

The adhesion, friction and wear properties of two ionic liquids, 1-butyl-3-methylimidazolium hexafluorophosphate ([BMIM]PF 6$)$ and 1-butyl-3-methylimidazolium octylsulfate ([BMIM][OctylSO 3$]$ ), applied on $\mathrm{Si}(100)$, was investigated using atomic force microscopy (AFM). Wear at ultra-low loads was simulated and the lubricant removal mechanism was investigated using AFM-based surface potential and contact resistance techniques. Thermally treated coatings containing a mobile lubricant fraction were able to protect the Si substrate from wear compared to the fully bonded coatings, and this enhanced protection is attributed to lubricant replenishment.

MEMS devices coated with a thin film of ionic liquid showed significant improvement in wear life $[64,65]$. A method that is based on atomic force microscopy (AFM) with a liquid cell has been developed [64] to study friction and wear properties of surfaces lubricated with ILs. The friction and wear data obtained for these tests showed good correlation with the failure life span of lubricated microelectrical mechanical systems (MEMS) motors.

The understanding and the improvement of wear of the tip during its contact with the ferroelectric materials is critical, particularly at the high scanning velocities needed for high data rate recording in the operating environments. To this end, adhesion, friction and wear experiments have been performed [66] using Pt-Ir coated tips sliding against unlubricated and lubricated lead zirconate titanate films. Two lubricants were used: perfluoropolyether and ionic liquid. The Pt-Ir tips are shown to exhibit lower wear against the lubricated ferroelectric film.

\section{IL-modified Nanostructures}

As it was anticipated [67], the unique combination of polar structure and the strong hydrogen bond interactions has open a new area of application of ILs as reaction media for the synthesis of nanostructured solids.

Recent reports have described the use of ILs as solvents for the synthesis of nanoparticles of palladium, platinum, iridium, gold, single-crystalline tellurium nanorods and nanowires by using ILs as solvents, and in surface functionalization of nanoparticles [67,68]. IL-modification (Figure 9) produces liquid-like organic salts and allows to enhance processability, and a variety of $\mathrm{ZnO}$ nanoparticles morphologies has been described in ILs media. 
Figure 9. IL modified nanoparticles and nanotubes.
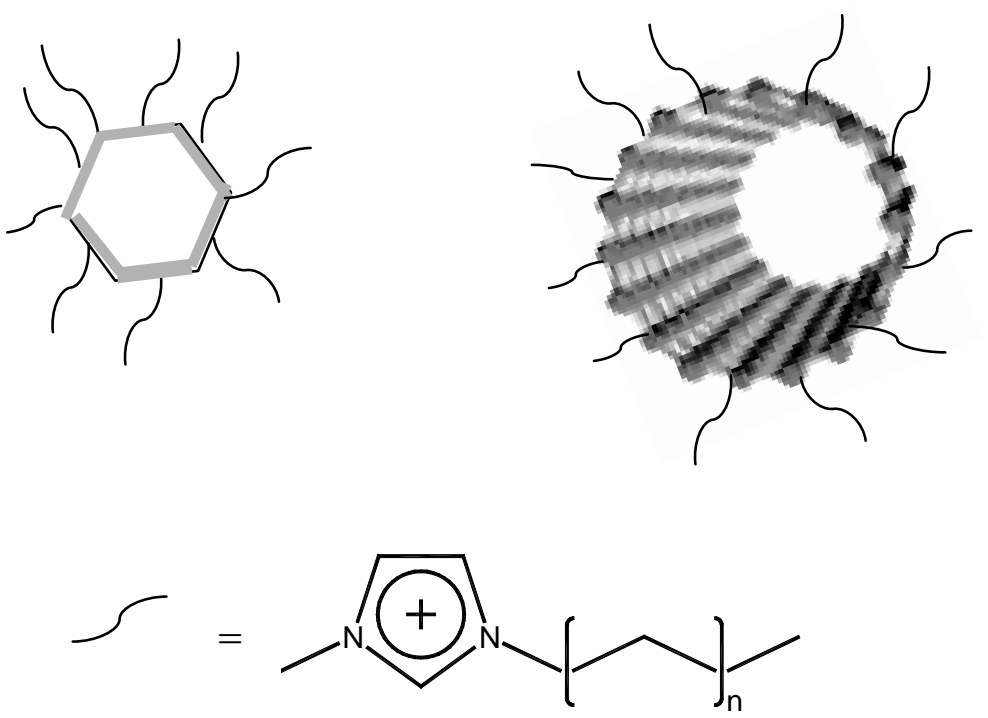

Fukushima et al. [69], found that single-walled carbon nanotubes (SWCNTs) can be readily dispersed in imidazolium IL by mechanical milling. The IL interacts with SWCNT (Figure 9) through van der Waals interactions and shields the strong $\pi-\pi$ stacking interaction between SWCNTs, thus stabilizing their dispersion [70].

The new SWCNT-IL bucky gel has been used in the preparation of a new plastic actuator, and polymerization of the gel produces a mechanically reinforced electrical and thermal conductive soft material [71,72].

IL/multi-walled carbon nanotubes (MWCNTs) have been prepared by chemical modification The new IL/MWNTs composite was evaluated as lubricant additive in IL due to their excellent dispersibility. It has been found that IL/MWCNTs showed good friction-reduction and anti-wear properties [73].

\section{Polymer Nanocomposites}

Because ILs are stable liquids over a wide temperature range, they offer technological advantages over some chemicals used in their liquid phase, such as plasticizers, where polymer flexibility can be enhanced. Common problems with plasticizers include evaporation and leakage from the surface, instability at high temperatures, lack of lubrication at low temperatures, migration within the polymer, and toxicity. Systems studied include polymethylmetacrylate (PMMA) plasticized with hexafluorophosphate [PF 6 ILs [8].

Ionic liquids as plasticizers might produce though flexible polymers. The lubricating ability of ILs has also been shown in polymers, both as external lubricants of polymer/steel systems and as polymer additives [22,74-76].

The tribological properties of polyamide (PA6) containing the ionic liquid 1-hexyl-3-methyl

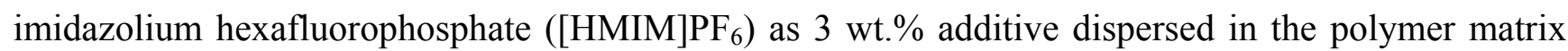
have been studied at variable temperatures. The IL-modified polymer maintains a low friction coefficient in the whole range of temperatures with values similar or even lower to that obtained when 
IL is used as external lubricant. [HMIM] $\mathrm{PF}_{6}$ has been added [76] to the polycarbonate (PC) nanocomposite $(\mathrm{PC}+0.5 \mathrm{wt} . \% \mathrm{ZnO})$ in a $1.5 \mathrm{wt} . \%$ proportion, to obtain $\mathrm{PC}+0.5 \% \mathrm{ZnO}+1.5 \% \mathrm{IL}$.

The new nanocomposite shows a $80 \%$ friction reduction and a wear reduction of nearly two orders of magnitude with respect to $\mathrm{PC}+0.5 \% \mathrm{ZnO}$. This good tribological performance is attributed to the improvement in $\mathrm{ZnO}$ dispersion within the PC matrix due to surface modification (Figure 10) of the nanophase by the IL.

Figure 10. TEM micrographs of: a) Neat $\mathrm{ZnO}$ nanoparticles; b) IL-modified $\mathrm{ZnO}$ nanoparticles within PC matrix.

a)

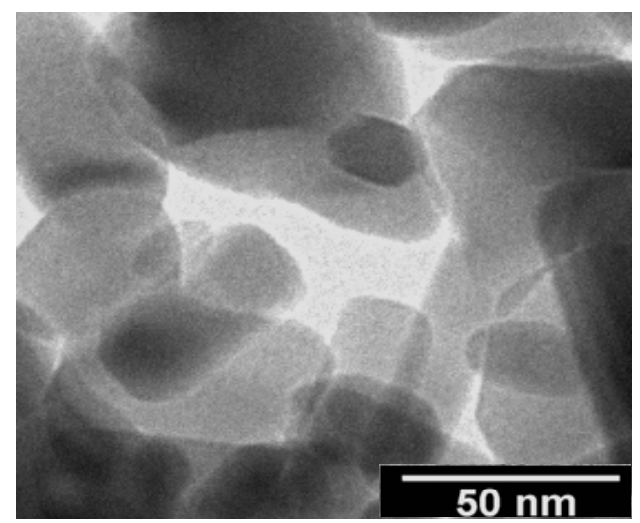

b)

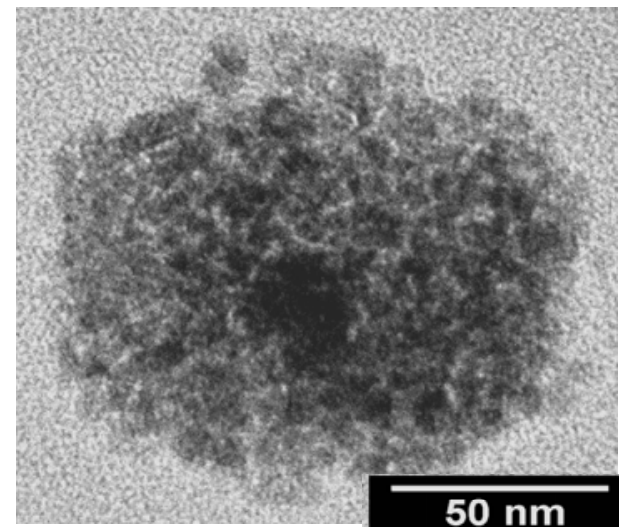

\section{Conclusions and Outlook}

The results reported here show that ILs are a family of new high performance lubricants [77] which may find commercial and technological applications where other lubricants are not suitable or fail to prevent friction, wear and surface damage of materials.

An adequate IL lubricant should be found for use in environments such as high vaccum, extreme temperatures and high pressures. To achieve this, a larger number of ILs should be tested under variable conditions. The surface interactions and tribochemical reactions of ILs with the sliding counterparts need to be thoroughly examined in order to ensure the formation of protecting tribofilms and to avoid corrosion.

The strategies followed so far to avoid severe tribocorrosion, particularly in the case of fluorinecontaining ILs, include the use of reactive ILs as lubricant additives rather than as neat lubricants, and the addition of corrosion inhibitor additives to IL lubricants. The synergistic effect and long-term stability of these mixtures need to be further investigated.

The IL-lubricated sliding contacts that have been reported are mainly steel-steel, steel-aluminium, steel-ceramic and ceramic-ceramic. More information is needed about the feasibility of the use of IL lubricants in contact with cryogenic or high temperature materials.

Very limited work has been reported on polymer lubrication by ILs and polymer-IL interactions in new nanocomposites. Promising results have been obtained in the used of IL-modified nanophases in lubrication, but further tribological studies should follow. 
Finally, a complete model of surface interactions and IL organization and structure is still to be developed. Many questions remain to be answered, but this will be the subject of the efforts of the growing number of researchers that are incorporating to this research area.

For commercial implementation ionic liquids still need to meet a number of requirements such as cost, stability and toxicity and environmental considerations. Some attempts are already been made to develop ILs from cheap starting materials [78].

Most ILs presented here contain halogen atoms and may release toxic and corrosive hydrogen halides to the environment $[79,80]$. New halogen-free ILs are being developed to avoid corrosion and toxicity [81], but few toxicological and/or ecotoxicological data are available for ILs until now.

\section{Acknowledgements}

We wish to thank the Spanish Science and Innovation Ministry (MICINN), the European FEDER program (MAT2008-01670) and the Fundación Séneca Program of Scientific Knowledge of Excellence (08596/PI/08).

\section{References}

1. Dupont, J. On the solid, liquid and solution structural organization of imidazolium ionic liquids. $J$. Braz. Chem. Soc. 2007, 15, 341-350.

2. Padua, A.A.H.; Canongia Lopes, J.N.A. Intra- and intermolecular structure of ionic liquids: from conformers to nanostructures. In Ionic Liquids IV. Not Just Solvents Anymore. Brenecke, J.F., Rogers, R.D., Seddon, K.R., Eds.; ACS Symposium Series 975; American Chemical Society: Washington, DC, 2007; pp. 86-101.

3. Consorti, C.S.; Suarez, P.A.Z.; de Souza, R.A.; Farrar, D.H.; Lough, A.J.; Loh, W.; da Silva, L.H.M.; Dupont, J. Identification of 1,3-dialkylimidazolium salt supramolecular aggregates in solution. J. Phys. Chem. B 2005, 109, 4341-4349.

4. Earle, M.J.; Esperança, J.M.S.S.; Gilea, M.A.; Canongia Lopes, J.N.; Rebelo, L.P.N.; Magee, J.W.; Seddon, K.R.; Widegren, J.A. The distillation and volatility of ionic liquids. Nature 2007, 439, 831-834.

5. Chauvin, Y.; Olivier-Boubigou, H. Nonaqueous ionic liquids as reaction solvents. Chem. Tech. 1995, 25, 26-30.

6. Holbrey, J.D.; Seddon, K.R. Ionic liquids. Clean Prod. Process 1999, 1, 223-236.

7. Rodriguez, H.; Williams, M.; Wilkes, J.S.; Rogers, R.D. Ionic liquids for liquid-in-glass thermometers. Green Chem. 2008, 10, 501-507.

8. Scott, M.P.; Benton, M.G.; Rahman, M.; Brazel, C.S. Plasticizing effects of imidazolium salts in PMMA: High-temperature stable flexible engineering materials. In Ionic Liquids As Green Solvents: Progress and Prospects; ACS Symposium Series 856; American Chemical Society: Washington, DC, 2003; pp. 468-477.

9. Wasserscheid, P.; Gerhard, D.; Arlt, W. Ionic liquids as operating fluids in high pressure applications. Chem. Eng. Tech., 2007, 30, 1475-1480.

10. Keskin, S.; Kayrak-Talay, D.; Akman, U.; Hortacsu, O. A review of ionic liquids towards supercritical fluid applications. J. Supercrit. Fluids 2007, 43, 150-180. 
11. Zhao, H. Innovative applications of ionic liquids as "green" engineering liquids. Chem. Eng. Commun. 2006, 193, 1660-1677.

12. Hough, W.L.; Rogers, R.D. Ionic liquids then and now: From solvents to materials to active pharmaceutical ingredients. Bull. Chem. Soc. Japan 2007, 80, 2262-2269.

13. Minami, I. Ionic liquids in tribology. Molecules 2009, 14, 2286-2305.

14. Borra, E.F.; Seddiki, O.; Angel, R.; Eisenstein, D.; Hickson, P.; Seddon, K.R.; Worden, S.P. Deposition of metal films on a ionic liquid as a basis for a lunar telescope. Nature 2007, 447, 979-981.

15. Stachowiak, G.W.; Batchelor, A.W. Engineering Tribology, 3rd ed.; Butterworth-Heinemann: Boston, MA, USA, 2005.

16. Wilkes, J.S.; Leviski, J.A.; Wilson, R.A.; Hussey, C.L. Dialkylimidazolium chloroaluminate melts: a new class of room-temperature ionic liquids for electrochemistry, spectroscopy and synthesis. Inorg. Chem. 1982, 21, 1263-1264.

17. Wilkes, J.S.; Zaworotko, M.J. Air and water stable 1-ethyl-3-methylimidazolium based ionic liquids. Chem. Commun. 1992, 965-967.

18. Ye, C.F.; Liu, W.M.; Chen, Y.X.; Yu, L.G. Room-temperature ionic liquids: a novel versatile lubricant. Chem. Commun. 2001, 2244-2245.

19. Liu, W.M.; Ye, C.F.; Gong, Q.Y.; Wang, H.Z.; Wang, P., Tribological performance of roomtemperature ionic liquids as lubricant. Tribol. Lett. 2002, 13, 81-85.

20. Liu, W.; Ye, C.; Chen, Y.; Ou, Z.; Sun, D.C. Tribological behavior of sialon ceramics sliding against steel lubricated by fluorine-containing oils. Tribol. Int. 2002, 35, 503-509.

21. Ye, C.F.; Liu, W.M.; Chen, Y.X.; Ou, Z.W. Tribological behavior of Dy-sialon ceramics sliding against $\mathrm{Si}_{3} \mathrm{~N}_{4}$ under lubrication of fluorine-containing oils. Wear 2002, 253, 579-584.

22. Sanes, J.; Carrion, F.J.; Bermudez M.D.; Martinez-Nicolas, G. Ionic liquids as lubricants of polystyrene and polyamide 6-steel contacts. Preparation and properties of new polymer-ionic liquid dispersions. Tribol. Lett. 2006, 21, 121-133.

23. Forsyth, M.; Neil, W.C.; Howlett, P.C.; Macfarlane, D.R.; Hinton, B.R.W.; Rocher, N.; Kemp, T. F.; Smith, M.E. New insights into the fundamental chemical nature of ionic liquid film formation on magnesium alloy surfaces. ACS Appl. Mater. Interfaces 2009, 1, 1045-1052.

24. Caporali, S.; Ghezzi, F.; Giorgetti, A.; Lavacchi, A.; Tolstogouzov, A.; Bardi, U. Interaction between an imidazolium based ionic liquid and the AZ91D magnesium alloy. Adv. Eng. Mater. 2007, 9, 185-190.

25. Bardi, U.; Chenakin, S.P.; Lavacchi, A.; Pagura, C.; Tolstogouzov, A. Sputter depth profiling by secondary ion mass spectrometry coupled with sample current measurements. Appl. Surf. Sci. 2006, 252, 7373-7382.

26. Birbilis, N.; Howlett, P.C.; Macfarlane, D.R.; Forsyth, M. Exploring corrosion protection of Mg via ionic liquid pre-treatment. Surf. Coat. Technol. 2007, 201, 4496-4504.

27. Forsyth, M.; Howlett, P.C.; Tan, S.K.; MacFarlane, D.R.; Birbilis, N. An ionic liquid surface treatment for corrosion protection of magnesium alloy AZ31. Electrochem. Solid State Lett. 2006, 9, B52-B55. 
28. Howlett, P.C.; Neil, W.; Khoo, T.; Sun, J.Z.; Forsyth, M.; MacFarlane, D.R. An electrochemical impedance study of ionic liquid film formation and aqueous corrosion of magnesium alloy ZE41. Isr. J. Chem. 2008, 48, 313-318.

29. Shkurankov, A.; El Abedin, S.Z.; Endres, F.; AFM-assisted investigation of the corrosion behaviour of magnesium and AZ91D alloys in an ionic liquid with varying water content. Aus. $J$. Chem. 2007, 60, 35-42.

30. Mu, Z.G.; Zhou, F.; Zhang, SX.; Liang, Y.M.; Liu, W.M. Effect of the functional groups in ionic liquid molecules on the friction and wear behavior of aluminum alloy in lubricated aluminum-onsteel contact. Tribol. Int. 2005, 38, 725-731.

31. Mu, Z.G.; Wang, X.X.; Zhang, S.X.; Liang, Y.M.; Bao, M.; Liu,W.M. Investigation of tribological behavior of Al-Si alloy against steel lubricated with ionic liquids of 1diethylphosphonyl-n-propyl-3-alkylimidazolium tetrafluoroborate. J. Tribol.-Trans. ASME 2008, 130, Art. No. 034501.

32. Jimenez, A.E.; Bermudez, M.D.; Iglesias, P.; Carrion, F.J.; Martinez-Nicolas, G. 1-N-alkyl-3methylimidazolium ionic liquids as neat lubricants and lubricant additives in steel-aluminium contacts. Wear 2006, 260, 766-782.

33. Jimenez, A.E.; Bermudez, M.D., Ionic liquids as lubricants for steel-aluminum contacts at low and elevated temperatures. Tribol. Lett. 2007, 26, 53-60.

34. Jimenez, A.E.; Bermudez, M.D.; Iglesias, P.; Carrion, F.J.; Martinez-Nicolas, G. 1-N-alkyl-3methylimidazolium ionic liquids as neat lubricants and lubricant additives in steel-aluminium contacts. Wear 2006, 260, 766-782.

35. Jimenez, A.E.; Bermudez, M.D.; Imidazolium ionic liquids as additives of the synthetic ester propylene glycol dioleate in aluminium-steel lubrication. Wear 2008, 265, 787-798.

36. Jimenez, A.E.; Bermudez, M.D.; Carrion, F.J.; Martinez-Nicolas, G.; Room temperature ionic liquids as lubricant additives in steel-aluminium contacts: Influence of sliding velocity, normal load and temperature. Wear 2006, 261, 347-359.

37. Qu, J.; Truhan, J.J.; Dai, S.; Luo, H.; Blau, P.J. Ionic liquids with ammonium cations as lubricants or additives. Tribol. Lett. 2006, 22, 207-214.

38. Qu, J.; Blau, P.J.; Sheng, D.; Huimin, L.; Meyer, J.M.; Truhan, J.J. Tribological characteristics of aluminium alloys sliding against steel lubricated by ammonium and imidazolium ionic liquids. Wear 2009, 267, 1226-1231.

39. Iglesias, P.; Bermudez, M.D.; Carrion, F.J.; Martinez-Nicolas, G. Friction and wear of aluminium-steel contacts lubricated with ordered fluids. Neutral and ionic liquid crystals as oil additives. Wear 2004, 256, 386-392.

40. Bermudez, M.D.; Jimenez, A.E.; Martinez-Nicolas, G. Study of surface interactions of ionic liquids with aluminium alloys in corrosion and erosion-corrosion processes. Appl. Surf. Sci. 2007, 253, 7295-7302.

41. Jimenez, A.E.; Bermudez, M.D. Ionic liquids as lubricants of titanium-steel contact. Tribol. Lett. 2009, 33, 111-126.

42. Suzuki, A.; Shinka, Y.; Masuko, M., Tribological characteristics of imidazolium-based room temperature ionic liquids under high vacuum. Tribol. Lett. 2007, 27, 307-313. 
43. Wang, H.Z.; Lu, Q.M.; Ye, C.F.; Liu, W.M.; Cui, Z.J. Friction and wear behaviors of ionic liquid of alkylimidazolium hexafluorophosphates as lubricants for steel/steel contact. Wear 2004, 256, 44-48.

44. Phillips, B.S.; John, G.; Zabinski, J.S., Surface chemistry of fluorine containing ionic liquids on steel substrates at elevated temperature using Mossbauer spectroscopy. Tribol. Lett. 2007, 26, 85-91.

45. Jin, C.M.; Ye, C.F.; Phillips, B.S.; Zabinski, J.S.; Liu, X.Q.; Liu, W.M.; Shreeve, JM. Polyethylene glycol functionalized dicationic ionic liquids with alkyl or polyfluoroalkyl substituents as high temperature lubricants. J. Mater. Chem. 2006, 16, 1529-1535.

46. Zeng, Z.; Phillips, B.S.; Xiao, J.C.; Shreeve, JM, Polyfluoroalkyl, polyethylene glycol, 1,4bismethylenebenzene or 1,4-bismethylene-2,3,5,6-tetrafluorobenzene bridged functionalized dicationic ionic liquids: Synthesis and properties as high temperature lubricants. Chem. Mater. 2008, 20, 2719-2726.

47. Pensado, A.S.; Padua, A.A.H.; Comunas, M.J.P.; Fernandez, J. Relationship between viscosity coefficients and volumetric properties using a scaling concept for molecular and ionic liquids. $J$. Phys. Chem. B 2008, 112, 5563-5574.

48. Nooruddin, N.S.; Wahlbeck, P.G.; Carper, W.R. Molecular modeling of ionic liquid tribology: Semi-empirical bonding and molecular structure. J. Mol. Struct. Theochem. 2007, 822, 1-7.

49. Mazyar, O.A.; Jennings, G.K.; McCabe, C. Frictional dynamics of alkylsilane monolayers on $\mathrm{SiO} 2$ : effect of 1-n-butyl-3-methylimidazolium nitrate as a lubricant. Langmuir 2009, 25, 5103-5110.

50. Phillips, B.S.; Zabinski, J.S. Ionic liquid lubrication effects on ceramics in a water environment. Tribol. Lett. 2004, 17, 533-541.

51. Omotowa, B.A.; Phillips, B.S.; Zabinski, J.S.; Shreeve, J.M. Phosphazene-based ionic liquids: Synthesis, temperature-dependent viscosity, and effect as additives in water lubrication of silicon nitride ceramics. Inorg. Chem. 2004, 43, 5466-5471.

52. Ge, L.L.; Chen, L.P.; Guo, R. Microstructure and lubrication properties of lamellar liquid crystal in Brij30/[Bmim]PF6/H2O system. Tribol. Lett. 2007, 28, 123-130.

53. Yao, M.; Liang, Y.; Xia, Y.; Zhou, F.; Bisimidazolium Ionic Liquids as the High-performance antiwear additives in poly(ethylene glycol) for steel-steel contacts. ACS Appl. Mater. Interfaces 2009, 1, 467-471.

54. Liu, X.; Zhou, F.; Liang, Y.; Liu, W. Benzotriazole as the additive for ionic liquid lubricant: One pathway towards actual application of ionic liquids. Tribol. Lett. 2006, 23, 191-196.

55. Yu, B.; Zhou, F.; Pang, C.; Wang, B.; Liang, Y.; Liu, W. Tribological evaluation of $\alpha, \omega-$ diimidazoliumalkylene hexafluorophophate ionic liquid and benzotriazole as additive. Tribol. Int. 2008, 41, 797-801.

56. Kamimura, H.: Kubo, T.; Minami, I.; Mori, S.; Effect and mechanism of additives for ionic liquids as new lubricants. Tribol. Int. 2007, 40, 620-625.

57. Minami, I.; Watanabe, N.; Nano, H.; Mori, S.; Kukumoto, K.; Ohno, H. Aspartic acid-derived wear preventing and friction reducing agents for ionic liquids. Chem. Lett. 2008, 37, 300-301. 
58. Fox, M.F.; Priest, M.; Triblogical properties of ionic liquids as lubricants and additives: Part 1: Synergistic tribofilm formation between ionic liquids and tricresylphosphate. Proc. Inst. Mech. Eng. Part J-J. Eng. Tribol. 2008, 222, 291-303.

59. Palacio, M.; Bushan, B. Ultrathin wear-resistant ionic liquid films for novel MEMS/NEMS applications. Adv. Mater. 2008, 10, 1194-1198.

60. Patton, S.T.; Voevodin, A.A.; Vaia, R.A.; Pender, M.; Dianianti, S.J.; Phillips, B. Nanoparticle liquids for surface modification and lubrication of MEMS switch contacts. J. Microelectromech. Sys. 2008, 17, 741-746.

61. Jiang, W.Q.; Yu, B.; Liu, W.M.; Hao, J.C. Carbon nanotubes incorporated within lyotropic hexagonal liquid crystal formed in room-temperature ionic liquids. Langmuir 2007, 23, 8549-8553.

62. Zabinski, J.S.; Eapen, K.C.; Phillips, B.S.; Mantz, R.A.; Nainaparampil, J.J. Lubrication of MEMS by ionic liquids. Abs. Papers Amer. Chem. Soc. 2004, 227, U829-U829.

63. Bhushan, B.; Palacio, M.; Kinzig, B. AFM-based nanotribological and electrical characterization of ultrathin wear-resistant ionic liquid films. J. Coll. Interf. Sci. 2008, 317, 275-287.

64. Nainaparampil, J.J.; Eapen, K.C.; Sanders, J.H.; Voevodin, A.A. Ionic-liquid lubrication of sliding MEMS contacts: Comparison of AFM liquid cell and device-level tests. $J$. Microelectromech. Sys. 2007, 16, 836-843.

65. Nainaparampil, J.J.; Phillips, B.S.; Eapen, K.C.; Zabinski, J.S. Micro-nano behaviour of DMBIPF6 ionic liquid nanocrystals: large and small-scale interfaces. Nanotechnology 2005, 16, 2474-2481.

66. Bhushan, B.; Kwak, K.J. The role of lubricants, scanning velocity and operating environment in adhesion, friction and wear of Pt-Ir coated probes for atomic force microscope probe-based ferroelectric recording technology. J. Phys. Cond. Mater. 2008, 20, Art. No. 325240.

67. Antonietti, M.; Kuang, D.; Smarsly, B.; Zhou, Y.; Ionic liquids for the convenient synthesis of functional nanoparticles and other inorganic nanostructures. Angew. Chem. Int. Ed. 2004, 43, 4988-4992.

68. Liu, D.P.; Li, G.D.; Su, Y.; Chen, J.S.; Highly luminescent $\mathrm{ZnO}$ nanopcrystals stabilized by ionic liquid components. Angew. Chem. Int. Ed. 2006, 45, 7370-7373.

69. Fukushima, T, Kosaka, A, Ishimura Y, Yamamoto, T, Takigawa, T, Ishii, N, Aida, T, Molecular ordering of organic molten salts triggered by single-walled carbon nanotubes. Science 2003, 300, 2072-2074.

70. Wang, J.; Chu, H.; Li, Y. Why single-walled carbon nanotubes can be dispersed in imidazoliumbased ionic liquids. ACS Nano 2008, 2, 2540-2546.

71. Fukushima, T., Asaka, K., Kosaka, A., Aida, T., Fully plastic actuator through layer-by-layer casting with ionic liquid-based bucky gel. Angew. Chem. Int. Ed. 2005, 44, 2410-2413.

72. Fukushima, T.; Aida, T. Ionic liquids for soft functional materials with carbon nanotubes in ionic liquids. J. Amer. Chem. Soc. 2005, 127, 14867-14868.

73. Pei, X.; Xia, Y.; Liu, W.; Yu, B.; Hao, J. Polyelectrolyte grafted carbon nanotubes: Synthesis, reversible phase-transition behaviour and tribological properties as lubricant additives. J. Polym. Sci. Part A Polym. Chem. 2008, 46, 7225-7237. 
74. Sanes, J.; Carrion-Vilches, F.J.; Bermudez, M.D. New epoxy-ionic liquid dispersions. Room temperature ionic liquid as lubricant of epoxy resin-stainless steel contacts. E-Polymers 2007, Art. No. 005.

75. Sanes, J.; Carrion, F.J.; Jimenez, A.E.; Bermudez, M.D. Influence of temperature on PA 6-steel contacts in the presence of an ionic liquid lubricant. Wear 2007, 263, 658-662.

76. Carrion, F.J.; Sanes, J.; Bermudez, M.D. Effect of ionic liquid on the structure and tribological properties of polycarbonate-zinc oxide nanodispersion. Mater. Lett. 2007, 61, 4531-4535.

77. Zhou, F.; Liang Y.; Liu, W; Ionic liquid lubricants: designed chemistry for engineering applications. Chem. Soc. Rev. 2009, doi: 10.1039/b817899m.

78. Evans, C. New ionic liquids from cheap non-toxic sources - Saccharine solution to a toxic problem. Chem. Commun. 2004, C27.

79. Swatloski, R.P.; Holbrey, J.D.; Rogers, R.D. Ionic liquids are not always green: Hydrolysis of 1butyl-3-methylimidazolium hexafluorophosphate. Green Chem. 2003, 5, 361-363.

80. Jastorff, B.; Stormann, R.; Ranke, J.; Molter, K.; Stock, F.; Oberheitmann, B.; Hoffmann, W.; Hoffmann, J.; Nuchter, M.; Ondruschka, B.; Filser, J. How hazardous are ionic liquids? Structureactivity relationships and biological testing as important elements for sustainability evaluation. Green Chem. 2003, 5, 136-142.

81. Wasserscheid, P.; van Hal, R.; Bosmann, A. 1-n-Butyl-3-methylimidazolium ([bmim]) octylsulfate - an even 'greener' ionic liquid. Green Chem. 2002, 4, 400-404.

Sample availability: Not available.

(C) 2009 by the authors; licensee Molecular Diversity Preservation International, Basel, Switzerland. This article is an open-access article distributed under the terms and conditions of the Creative Commons Attribution license (http://creativecommons.org/licenses/by/3.0/). 